\title{
A marcha da integração no MERCOSUL: vivace ma non troppo
}

BALZE, Felipe A. M. de la (comp.). Argentina y Brasil: enfrentando el Siglo XXI. s.l. [Buenos Aires]: Consejo Argentino para las Relaciones Internacionales-Asociación de Bancos de la República Argentina, 1995, $487 \mathrm{p}$.

ZYLBERSTAIN, Hélio; RODRIGUES, Iram Jácome; CASTRO, Maria Silvia Portella de; VIGEVANI, Tullo (orgs). Processos de integração regional e sociedade: o sindicalismo na Argentina, Brasil, México e Venezuela. Rio de Janeiro: Paz e Terra, 1996, 381 p.

PABST, Haroldo. MERCOSUL: direito da integração. Rio de Janeiro: Forense, 1997, 278p.

PEREIRA, Ana Cristina Paulo. MERCOSUL: o novo quadro jurídico das relações comerciais na América Latina. Rio de Janeiro: Editora Lumen Juris, 1997, 208p.

BRANCO, Luizella Giardino B. Sistema de Solução de Controvérsia no MERCOSUL: perspectivas para a construção de um modelo institucional permanente. São Paulo: Editora LTr, 1997, 180 p.

VENTURA, Deisy de Freitas Lima: A ordem jurídica do MERCOSUL. Porto Alegre: Livraria do Advogado, 1996, 168 p.

MERCOSUL: acordos e protocolos na área jurídica. Porto Alegre: Livraria do Advogado, 1996, 153p.

A produção acadêmica e a literatura especializada sobre os processos de integração regional na América Latina e, em especial, sobre o Mercosul e o processo Brasil-Argentina, parecem finalmente estar encontrando, no Brasil, uma "velocidade de cruzeiro". As obras que são discutidas a seguir tratam todas dos desafios jurídicos, político-institucionais e econômicos da construção da integração regional, demonstrando que, se a sua marcha econômico-comercial adota o estilo andante-veloce, o ritmo jurídico-institucional conhece, por motivos diversos, um certo compasso de espera. Se os teóricos e “juristas” da integração impacientam-se com a "resistência anticomunitária” dos burocratas governamentais, os empresários, agricultores e sindicatos operários manifestam visível preocupação com uma certa "pressa livre-cambista" que vigoraria sobretudo no vizinho do Prata. 
É precisamente da Argentina que nos vem o primeiro dos livros compulsados neste artigo-resenha, aliás o único da meia dúzia de obras aqui discutidas, confirmando plenamente a fama de boa qualidade analítica dos estudos publicados na outra margem do Prata. Ele foi organizado por Felipe de la Balze para o CARI, o Conselho Argentino de Relações Internacionais.

Na parte da "política”, comparece em primeiro lugar Torcuato Di Tella, o grande sociólogo, irmão do atual chanceler do Presidente Menem, com uma análise do sistema político brasileiro na perspectiva argentina. Como tal, ele não apresenta maiores novidades para um leitor brasileiro, não fosse sua leitura relativamente exaustiva do itinerário político do Brasil desde a era Vargas, na verdade desde 1808 e com especial ênfase a partir do tenentismo, esse peronismo avant la lettre que presidiu à modernização do país a partir dos anos 30. Mais interessante é sua análise do posicionamento das principais forças políticas do Brasil - partidos, empresários, sindicatos - em face dos grandes problemas de política econômica ou das opções colocadas aos setores econômicos (aço, automóveis, bens de capital, indústrias diversas) que, pelo seu natural dinamismo, apresentam importante impacto no processo de integração conduzido com a Argentina desde meados dos anos 80 (baseado, no primeiro período, em acordos setoriais, precisamente).

Ohistoriador Jorge Hugo Herrera Vegas apresenta um estudo comparativo notávelmente sintético sobre as políticas externas da Argentina e do Brasil, nas quais ele identifica, desde as origens coloniais, "divergências e convergências", isto é, pontos de dissenso e de aproximação nas posturas bilaterais, multilaterais e com terceiros países, vale dizer, com os Estados Unidos, a ponta do triângulo inevitável na política pendular mantida por um e outro país em diferentes épocas de uma história sempre complexa, mas raramente conflitiva a ponto de precipitar guerras ao estilo França-Alemanha. Ainda assim, a releitura do contencioso bilateral em torno do aproveitamento dos recursos hídricos do Paraná, nos anos 70 , segundo a perspectiva argentina ébastante instrutiva, da mesma forma como a busca das "origens" do processo de integração. Para Vegas, a história paralela das duas políticas exteriores demonstra que os dois países, Brasil e a Argentina, "nacen con polaridades geográficas e históricas opuestas y van convergiendo progresivamente hasta sellar una unidad de destino en el Tratado de Asunción”; mais importante, ele também afirma que o debate, crucial durante a fase de transição, sobre a alternativa Mercosul ou NAFTA pode ser considerado como "superado" na Argentina.

Encerra essa parte da "política" um curto estudo "geopolítico" de Vicente Gonzalo Massot sobre a evolução dos dois países, de um "equilíbrio de 
inimizades à cooperação bilateral”, no qual são examinadas as muitas incompreensões, de parte e outra, mantidas por diplomatas e militares dos dois lados do Prata sobre as intenções respectivas de seus governos sobre o sentido geral da projeção estratégica de cada um e com respeito a armamentos, inclusive o nuclear. Trata-se de um itinerário ainda não concluído que deveria levar, segundo o autor, à desejada “defesa cooperativa”.

A parte de “economia” tem início por extenso trabalho de Elvio Baldinelli sobre o comércio bilateral, no qual, além de uma análise dos fluxos, se discute também o problema das paridades cambiais e o dos incentivos fiscais e creditícios, os principais pontos remanescentes de assimetria nas políticas macroeconômicas dos dois países. Para a primeira questão se sugere a adoção de um sistema de "banda de flutuações" a partir da paridade real das duas moedas e, para a segunda, a incorporação plena de todas as normas da Rodada Uruguai sobre a matéria. O estudo seguinte, a cargo de Roberto Bouzas, traça um panorama completo das políticas nacionais em matéria de investimento estrangeiro, assinalando as divergências (e restrições ao tratamento nacional) ainda existentes nos regimes respectivos e seus efeitos sobre os fluxos internos e externos nessa área, sumarizando também os movimentos de negócios que foram registrados reciprocamente no decorrer do processo de integração. Adalberto Rodrigues Giavarini opera uma brilhante análise comparada dos setores financeiros respectivos, ambos emergentes de uma história pregressa de inflação descontrolada e adaptando-se duramente aos requisitos de uma economia estabilizada. Finaliza a parte econômica um estudo de Eduardo Fasulino sobre as políticas de concorrência nos dois países, setor de crescente significação na medida em que o aprofundamento da integração torna cruciais os aspectos regulatórios e macroestruturais que enquadram a competição entre empresas da região na busca de maior acesso a mercados e de condições equitáveis de concorrência.

O capítulo mais importante do livro écontudo o primeiro, no qual Felipe de la Balze discorre sobre os desafios que a Argentina enfrenta nesta passagem de milênio para assegurar uma taxa adequada de crescimento econômico, criar um sistema institucional legítimo e inserir-se exitosamente na economia e na política mundiais. Em sua opinião a estratégia de seu país deveria desenvolverse em duas etapas: consolidar o processo de integração econômica e de cooperação política com o Brasil e, simultaneamente, aprofundar o acercamento bilateral com os Estados Unidos, tanto nos temas estratégicos como nos econômicos. Sua análise nos parece pecar aqui por um certo voluntarismo, pois ele vislumbra a possibilidade de um acordo de cooperação militar entre os países 
do Mercosul e a OTAN, ao mesmo tempo em que se desenvolveria uma rede de relações privilegiadas com o NAFTA e com a União Européia.

O organizador desse importante livro apresenta em seu capítulo os cinco desafios do processo atual de integração: aprofundamento do Mercosul, reforço das alianças regionais e extra-regionais (ALADI, NAFTA e UE), coordenação macroeconômica, coordenação das políticas de comércio exterior e de promoção comercial e, finalmente, o da institucionalização, no qual se descarta a tese da supranacionalidade, mas se recomenda fortemente um Tribunal de Justiça supranacional, independente e imparcial. A “estratégia central” de seu cenário para o século XXI está fortemente baseada numa aliança privilegiada com os Estados Unidos e numa “convergência” com o Primeiro Mundo, como se tal tipo de política unilateral pudesse produzir respostas cooperativas e promessas efetivas de incorporação no centro de poder em nível mundial.

Os textos recolhidos no volume da Paz e Terra sobre os processos de integração regional e o sindicalismo em países da América Latina resultaram de seminário organizado cooperativamente em 1995 pelo Instituto de Estudos Avançados da USP e pela Associação Brasileira de Estudos do Trabalho. Os autores (da Argentina, Brasil, México e Venezuela) se posicionam nitidamente numa postura contrária ao neoliberalismo aparentemente dominante nas esferas governamentais desses países e tendem a colocar em termos realistas os desafios colocados às centrais sindicais em face do que é chamado de "transição liberalmodernizadora" no continente.

Diversos fatores levaram todos os movimentos sindicais nos países considerados a verdadeiras encruzilhadas, tendo eles próprios de operar uma reconversão dos métodos de ação e um ajuste adaptativos às novas regras do jogo: não só mudam os parâmetros pelos quais se definiam a autonomia e a iniciativa sindicais (supondo-se que elas existissem em países como México e Argentina) como o próprio conceito de poder coletivo de barganha das centrais nacionais. Hoje há uma maior informalização das relações trabalhistas e uma precariedade acentuada nas condições de emprego. O sindicalismo é de certa forma preservado naquelespaíses, como o Brasil, onde ele pode participar de conselhos ou estruturas consultivas de tipo corporativo (câmaras setoriais), o que significa que sua manutenção se dá pela participação cada vez maior no sistema político. Iram Rodrigues e Hélio Zylberstain, num texto sobre o Brasil, chamam esse tipo de interação de “cooperação conflitiva”, ao passo que as clientelas do setor público preservam grupos políticos radicais, identificados com a esquerda socialista.

Tullo Vigevani e João Paulo Veiga focalizam o que eles chamam de “dilema sindical no Mercosul”: internacionalismo ou protecionismo, mostrando as 
estratégias inovadoras adotadas pelas centrais da subregião, com intensa participação nos grupos de trabalho e nos debates sobre diretrizes de políticas setoriais e macroeconômicas, num contexto em que uma "Carta Social” muito abrangente e ambiciosa revela-se uma utopia.

Numbrilhante texto sobre a dimensão política do Mercosul, Monica Hirst identifica os atores de primeiro e de segundo plano do processo integracionistamercocratas, empresários e líderes políticos por um lado, partidos, pequenos empresários e sindicatos por outro - e discute os principais temas de politização desse processo: relações com o NAFTA, política industrial ou liberalização, temas sociais, possibilidade de cooperação política e, sobretudo a questão da institucionalidade:intergovernamental comopreferem os governos, ou supranacional como recomendam alguns teóricos.

Aquestão da definição de estruturas políticas e decisionais exclusivamente intergovernamentais ou moderadamente supranacionais encontra-se presente, com maior ou menor grau de detalhe, nos demais livros aqui analisados. $\mathrm{O}$ catarinense Haroldo Pabst, em utilíssimo manual que deve ser recomendado a todo estudante em direito econômico e comercial, enfoca o tema sob o prisma da uniformização jurídica do espaço integracionista, partindo dos métodos recomendados pelo Unidroit para examinar com mais ênfase as experiências da União Européia e do Mercosul.

Essa uniformização jurídica pode ser feita tanto pela via do direito internacional público como pela via do direito comunitário, opção retida no caso da Europa, ao passo que o Mercosul se vale ainda da primeira. O livro de Pabst é uma espécie de plaidoyer por essa uniformização, ressaltando que a construção do mercado comum a torna indispensável. Da mesma forma, diz ele, quando esse mercado comum for uma realidade, "a harmonização jurídica mais ampla e a instituição de órgãos supranacionais, inclusive do Tribunal de Justiça do Mercosul, serão inevitáveis”.

Muitos juristas, mesmo sem preconizar diretamente a criação de órgãos supranacionais, apontam a necessidade da construção jurisprudencial comunitária, ou pelo menos comum, em matéria de liberalização de mercados e de direito da concorrência, como por exemploWerter Faria. Pabst reconhece quea harmonização do Mercosul porvia de órgãos supranacionais definitivos está distante, mas insiste em que essa harmonização se dê agora, no momento da construção do mercado comum, no que ele tem perfeitamente razão: “Os mecanismos para o início imediato da harmonização existem e não há justificativa plausível para postergála”. Olivro, respondendo à dificuldade que têm muitos estudantes de encontrar os textos “fundacionais” daintegração européia e na região, trazum anexo documental 
com os tratados de Roma e deAssunção, os protocolos de Brasília e de Ouro Preto, bem como diversos outros instrumentos de cooperação em matéria jurisdicional entre os países do Mercosul.

O livro de Ana Cristina Pereira recolhe a primeira parte de sua tese de doutoramento na Universidade de Paris-I, sobre o novo quadro jurídico das relações comerciais na América Latina, enfocando mais particularmente as bases jurídicas e as regras de funcionamento do Mercosul. Trata-se de estudo minucioso dos diversos instrumentos da integração regional à luz do sistema multilateral regido pelo GATT e pelo direito dos tratados, tal como regulado pela Convenção de Viena de 1969.

A autora examina questões de grande relevância na construção de uma ordem jurídica no Mercosul, como a da aplicabilidade das decisões adotadas pelos órgãos intergovernamentais no âmbito interno dos Estados Partes, o sistema de solução de controvésias e a do próprio sistema de decisões previsto no Tratado de Assunção e no Protocolo de Ouro Preto. Ela também se dedica a uma análise das regras de funcionamento do Mercosul, em especial no que tange ao comércio de mercadorias, à livre circulação no território dos países membros e ao estabelecimento da união aduaneira. São igualmente enfocadas as regras sobre práticas comerciais restritivas e as políticas nacionais de apoio às exportações e subvenções à produção. A obra constitui uma boa aproximação à problemática integracionista no contexto mais vasto do sistema multilateral de comércio, adminstrado desde janeiro de 1995 pela Organização Mundial do Comércio.

Mais específico é o estudo de Luizella Giardino Branco, sobre o sistema de solução de controvérsias no Mercosul que, como seu subtítulo indica, pretende ofereceruma contribuição para a construção de um modelo institucional permanente. Resultado de uma tese de mestrado sob a orientação competente da Professora Nádia de Araujo, o trabalho faz um estudo comparado dos mecanismos de resolução de conflitos já existentes e em funcionamento na União Européia, no Pacto Andino e no NAFTA, para discutir o modelo do Mercosul numa perspectiva evolutiva, isto é, apontando tendencialmente para a constituição de um Tribunal supranacional. Essa opção não é meramente retórica ou derivada de uma preferência teórica pelo modelo de integração supostamente mais avançado, mas resulta de um cuidadoso estudo comparado e empírico das vantagens e deficiências de cada um dos sistemas de solução de controvésias selecionados no livro, vale dizer, as mais importantes experiências atualmente disponíveis no "supermercado" dos processos integracionistas.

Para a autora, a esfera jurídica é a "única que pode garantir a continuidade a longo prazo da integração, porque não se esgota com a instauração 
desta, mas ao contrário, acompanha o processo de desenvolvimento”. Daí sua reafirmação da essencialidade de um sistema jurídico adequado e da instituição de um Tribunal Supranacional: este "representaria não só a efetiva vontade política dos países em assegurar esse processo, como também concorreria para formar a harmonia e o respeito ao cumprimento do direito comunitário, requisito fundamental para preservar o laço associativo dos Estados-membros”. Este brilhante trabalho de uma jovem jurista, que merece mais ampla divulgação, vem precisamente reforçar o bloco daqueles que, ainda que reconhecendo o caráter prematuro de instituições supranacionais no Mercosul, advogam pela criação de uma corte arbitral ou de um tribunal permanente de justiça no âmbito do Cone Sul.

O livro de Deisy de Freitas Ventura, outra jovem pesquisadora, desta vez do Rio Grande do Sul, vai direto à questão mais importante, do ponto de vista dos juristas, no processo de construção do Mercosul: deve-se passar sem delongas à etapa do direito comunitário, erigindo uma ordem jurídica que se superponha às soberanias nacionais, ou caberia, ao contrário, como fazem de fato os governos dos países membros, avançar gradualmente, cuidadosamente, de molde a evitar rupturas políticas e econômicas muito graves no ainda frágil edifício integracionista ou fissuras institucionais irremediáveis se se decidisse por estender em demasia a viga mestra de sua sustentação jurídica?

A resposta da autora, nesta obra que também resulta de uma tese de mestrado, não deixa dúvidas quanto ao caminho por ela escolhido. Com efeito, $A$ ordem jurídica do MERCOSUL é, antes de mais nada, uma vibrante defesa de uma normatividade jurídica plenamente eficaz no Mercosul, contra a inércia “soberanista” dos Estados Partes. Trata-se, como já antevisto em várias outras obras de juristas e acadêmicos universitários, de uma demanda recorrente em livros e artigos de caráter jurídico-institucional, algo como um plaidoyer pro domo sua no estabelecimento oportuno da institucionalidade supranacional? O trabalho de Deisy Ventura está muito bem construído, apresenta sólida fundamentação teórica e discute os problemas pertinentes da atual fase de constituição de um edifício integracionista no Cone Sul. A autora começa por se perguntar se há uma ordem jurídica no Mercosul; para apresentar sua resposta ela começa por examinar as fontes do direito no "bloco integracionista”, para depois deter-se no exame de cada uma das constituições dos Estados Partes do Tratado deAssunção, para evidenciar o caráter restritivo de algumas disposições. A resposta à questão seria positiva caso se admita a interação das ordens jurídicas nacionais com os propósitos do instrumento constitutivo do futuro mercado comum, no pressuposto de que as decisões dos órgãos autônomos do Mercosul são ou possam ser 
integrados automaticamente no ordenamento interno de cada um dos Estados. Tal não parece ser entretanto o caso, daí a constatação de uma lacuna de ordem jurídica, na acepção do direito comunitário, o que parece bastante evidente a qualquer observador um pouco mais informado.

O Mercosul é certamente híbrido do ponto de vista institucional e não há porque pensar que o modelo comunitário europeu constitui o nec plus ultra dos padrões aceitáveis de construção de um mercado comum. Alógica do Mercosul é a do menor custo possível, político ou social, para não dizer econômico, daí a própria economia feita pelos países membros em número de mercocratas e outros gêneros de tecnocratas. Os juristas não se reconhecerão nessa descrição, podendo mesmo argumentar que a ordem legal éabsolutamente indispensável ao bom funcionamento de todo e qualquer empreendimento integracionista. Talvez, mas então o Mercosul se faz pelo método do ensaio e erro, da empiria consagrada em norma.

Asegunda grande questão levantada no trabalho de Deisy Ventura referese à possibilidade de formação de uma ordem jurídica comunitária no Mercosul. Aqui a resposta parece ter vindo ao mesmo tempo que a pergunta, pois se toma como óbvio o conceito oriundo do direito comunitário europeu, isto é, uma ordem autônoma e hierarquizada. Em outros termos, o Mercosul deveria ou precisaria aproximar-se do modelo europeu para receber uma espécie de label comunitário, uma certificação de origem supranacional. Contra essa perspectiva são levantados vários óbices estruturais e sobretudo políticos nos países membros. Adespeito de uma aceitação de princípio por parte das elites desses países dos pressupostos da construção comunitária - ou seja, a cessão de soberania, a delegação ou transferência de poderes, a limitação da vontade soberana do Estado - a internacionalização efetiva de suas economias respectivas ou uma ativa e assumida interdependência entre os países membros do Mercosul parece ainda distante. O problema aqui parece ser mais de ordem prática do que teórica: os economistas, que são os que de fato comandam o processo de integração, pelo menos em seus aspectos práticos, não têm o mesmo culto à noção de soberania - seja contra ou a favor - em que parecem deleitar-se os juristas. Não se trata de uma questão em relação à qual se possa ser contra ou a favor ou de uma noção para ser encaminhada ou resolvida por um tratado jurídico de qualquer tipo: a soberania não faz parte dos cálculos de PIB ou dos equilíbrios de balança comercial e não se sujeita à coordenação de políticas macroeconômicas, daí sua irrelevância prática para a condução efetiva do processo integracionista. Ela é, sim, exercida diariamente, na fixação da taxa de câmbio - que pode até ser declarada estável - ou na determinação do nível de proteção efetiva em situações 
de baixa intensidade integracionista, que é justamente aquela na qual vivem os países do Mercosul ou pelo menos o maior deles.

A autora acredita que "a vontade política e não o conceito de soberania são determinantes da opção pelo modelo supranacional” e que o Brasil, mesmo apresentando uma grande "influência externa em toda a condução de sua política econômica”, foi o “grande responsável pela compleição intergovernamental da estrutura orgânica mercosuliana”.

Dito isto, este resenhista pretende deixar claro que não defende uma posição "soberanista" estrita no processo de construção, necessariamente progressivo e gradual, do Mercosul. A soberania, como no velho mote sobre o patriotismo, costuma ser o apanágio dos que se atêm à forma em detrimento do conteúdo, à letra em lugar do espírito da lei; sua afirmação, em caráter peremptório ou irredentista, égeralmente conservadora, podendo mesmo sua defesa exclusivista e principista ser francamente reacionária no confronto com as necessidades inadiáveis de promoção do desenvolvimento econômico e social e do bem-estar dos povos da região. O que, sim, deve ser considerado na aferição qualitativa de um empreendimento tendencialmente supranacional como é o caso do Mercosul é em que medida uma renúncia parcial e crescente à soberania por parte dos Estados Partes acrescentaria "valor" ao edifício integracionista e, por via dele, ao bem-estar dos povos integrantes do processo, isto é, como e sob quais condições especificamente uma cessão consentida de soberania contribuiria substantivamente para lograr índices mais elevados de desenvolvimento econômico e social.

A última questão analisada no libro de Deisy Ventura refere-se à eficácia jurídica no âmbito do Mercosul, terreno no qual a boa técnica jurídica nos incita a concordar com as pertinentes observações da autora. Que as instituições nacionais sejam as boas guardiãs das normas de direito no quadro do Mercosul parece repugnar ao jurista cioso da enforceability dos atos constitutivos do processo de integração. Quem guarda o guarda?, seria o caso de se perguntar, numa analogia tão latina quanto brasileira. As deficiências da ordem jurídica do Mercosul nesse particular são reais, o que nos faz concordar com a autora no sentido em que esse componente (a baixa eficácia dos fatos jurídicos gerados pelas regras do Mercosul) “determina a instabilidade e a insegurança destas relações jurídicas, atributos que se multiplicarão com o aprofundamento do processo integracionista”.

O livro de Deisy Ventura é utilmente complementado, em dois anexos, pelo texto do Protocolo de Ouro Preto e por dispositivos selecionados (relativos aos temas internacionais e integracionistas) das mais importantes constituições européias, o que se constitui em valioso auxílio documental aos estudantes universitários brasileiros. 
Com vistas, justamente, a municiar estudantes e pesquisadores com o conhecimento adequado dos principais instrumentos jurídicos existentes no âmbito do Mercosul, o Ministério da Justiça (por meio de sua assessoria internacional, sob a responsabilidade do diplomata Roberto Furian Ardenghy), o Mestrado em Integração Latino-Americana da Universidade Federal de Santa Maria (coordenado pelo competente Professor Ricardo Seitenfus) e a Livraria do Advogado do Porto Alegre vêm oferecer a coletânea dos textos dos acordos e protocolos firmados na área jurídica pelos Estados Partes do Tratado de Assunção: os nove instrumentos publicados na íntegra vêm acompanhados de seu respectivo índice alfabético-remissivo, o que facilita a consulta aos diversos elementos constitutivos dos atos de cooperação jurídica estabelecidos no âmbito da reunião de ministros da justiça do Mercosul. Esse foro se ocupa de importantes questões jurídicas e administrativas, cobrindo desde o estudo da consolidação de um direito comunitário até problemas eminentemente práticos como o tráfico de menores e a lavagem de dinheiro.

Os sete livros aqui examinados contribuem, de diversos modos, para o aprofundamento de um debate que se tornou inadiável no Mercosul: o do reforço de sua institucionalidade com vistas a enfrentar os desafios que são colocados de contínuo aos Estados membros, sobretudo no âmbito hemisférico (ALCA) e na esfera multilateral (OMC). Eles oferecem algumas armas teóricas, vários argumentos jurídicos de excelente qualidade técnica e uma boa visão comparativa sobre como o Mercosul pode continuar sua marcha segura em direção do almejado mercado comum, talvez não sem os atropelos políticos, sociais ou econômicos da globalização, mas pelo menos segundo um processo ditado exclusivamente pela conveniência dos interesses de seus povos respectivos.

Paulo Roberto de Almeida

SARAIVA, José Flávio Sombra. O lugar da África: a dimensão atlântica da política externa brasileira (de 1946 a nossos dias). Brasília: EdUnB, 1997, 280 páginas.

A coleção Relações Internacionais (da Editora da Universidade de Brasília), coordenada pelo professor Amado Luiz Cervo, acaba de lançar uma importante obra sobre a política africana do Brasil e as relações Brasil-África, de 